\title{
Personalized roll call service based on beacon indoor positioning technology for intelligent campus
}

\author{
Jian-Wei Li*, Yi-Chun Chang**, De-Yao Huang** and Min-Xiong Xu** \\ * Department of Information and Communications, Chaoyang University of Technology \\ 168, Jifeng E. Rd., Wufeng District \\ Taichung, Taiwan (R.O.C.) \\ (lijw@cyut.edu.tw) \\ ** Department of Computer Science and Information Engineering, Hungkuang University \\ No. 1018, Sec. 6, Taiwan Boulevard, Shalu District \\ Taichung, Taiwan (R.O.C.) \\ changyc@hk.edu.tw
}

\begin{abstract}
This paper proposes a roll call service based on beacon technology for class, which can instead of the traditional hard copy to save time and effort for teachers and learners. According to the personal curriculum, the proposed roll call service applies push technology to remind the user that the class information includes the class time and the classroom location in campus. By using beacon indoor positioning technology, the proposed roll call service can validate the position of the user.
\end{abstract}

Key words: beacon, indoor positioning technology, intelligent campus

\section{Introduction}

With the original purpose of low power consumption in design, the Bluetooth Low Energy (BLE) [1] technology characteristic of signals emitted within a few meters and intermittent data transmission has come to the fore in applications of the Internet of Things[2] The BLE-based micro-positioning transmitter also known as Beacon runs to regularly broadcast self-signals which are captured by a BLE receiver for reading the Beacon's one and only ID as the unique identification. Furthermore, Beacon signals available in several meters function as micro-positioning from 2 to 100 meters and is more accurate indoors than GPS positioning [3]

The roll call process in a classroom which takes some time usually. Instead of the printed roll call carried additionally and archived uneasily, the roll call supported by an electronic product in an era of science and technology advanced is competent in processing of data reliably. For learners, providing learning guidance and assistance while encountering learning problems is critical to promote the learning quality [4] For instructors, adjusting the teaching way and materials according to learners' situations can promote the teaching quality [5] .

However, an instructor's laptop computer or a class computer system for the computer-based roll call might not be moved easily. Accordingly, the Beacon-based indoor positioning technology for verification of a personal identity proposed in this research embodies an automatic roll call system in an intelligent campus and the insensitive roll call in a classroom, featuring multiple personalized functions such as school hour reminder, automated roll call and individual interaction in a classroom.

\section{System design}

The Beacon-based indoor positioning technology is available in a campus in which lots of students or participants register at the specific time or location. In a classroom in which students aggregate, the signals from a Beacon device will be searched by a mobile phone app automatically and checked with a course schedule in a database for completion of the insensitive roll call which is sent back to a student through the push technology. Moreover, a personalized design with which a course schedule or roll call history this semester (a class schedule or the attendances of students for class management) is checked will be available to a student (an instructor). As shown in Fig 1, the identities of users administered by the Beacon-based indoor micro-positioning system are "learner" and "instructor":

The attendance of a learner who had enabled his/her mobile phone app once will be checked in the background insensitive roll call later; the attendance of a learner, which is checked in the background insensitive roll call with no mobile phone app enabled as usual, is broadcasted through the push technology. Moreover, a personalized course schedule accessed by a learner reminds the learner of his/her attendance at one class by color, e.g., "checked" in blue, "not checked" in red or "absent" in white.

The attendances of learners are displayed in a personalized course schedule and read by an instructor. For example, an instructor reviews the numbers of learners, present or absent, in the roll call by date or class and checks details of an individual learner.

A learner, who enabled a specific app installed in his/her mobile phone for the background execution before arriving at the classroom, is able to review his/her personalized course schedule, which is displayed through the web server, by the learner profile server as well as the course schedule server and reminded of the class time and the classroom via the push technology. When a learner enters a classroom on time, the signals emitted from a Beacon device inside the classroom are searched by the learner's mobile phone within the scanned area of the Beacon device automatically. Then, a background insensitive roll call is enabled with the course schedule server 
checking data in a database through WiFi and the internet.

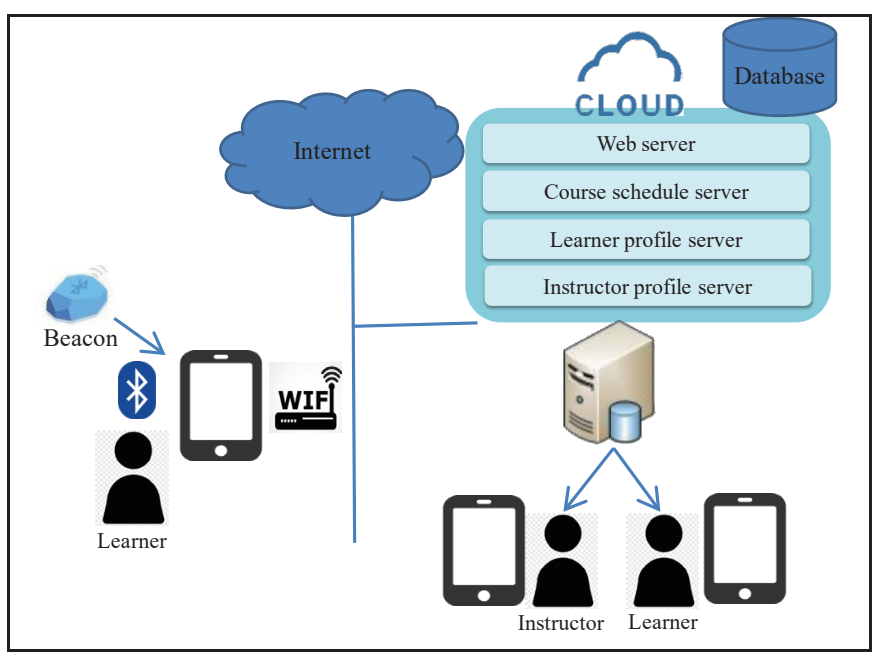

Fig. 1 System architecture

\section{Execution Procedure}

(1) An instructor logins the Beacon-based indoor micro-positioning system for identity verification through a web server.

(2) The instructor's identity compared with data in a database is verified by an instructor profile server.

(3) The information of a personalized operation enabled is sent back to the instructor through the web service with the learner's identity verified by the instructor profile server.

(4) The personalized function, "course schedule inquiry", is executed by the instructor through the web server with the database checked via the instructor profile server and the course schedule server.

(5) The personalized course schedule is transmitted with the connectivity between the course schedule server and the database completed.

(6) The personalized course schedule is sent back through the web server and displayed to the instructor.

(7) The roll call function for learners who have entered a specific classroom is enabled automatically with the course schedule server checking the database.

(8) The status of learners attending the class is sent back through the web server and displayed to the instructor.

(9) The personalized function, "roll call history", for each learner can be enabled by the instructor through the web server.

(10) The roll call history checked in the database by the instructor profile server is sent back through the web server and displayed to the instructor.

\section{Conclusion}

Compared with other identity verification systems based on NFC or RFID technologies, the Beacon-based indoor micro-positioning system simplifies purchases and installations of extra devices significantly without excessive resource consumption such as proximity card.

The personal identity verification technology in an intelligent campus is an initial step to fulfill the insensitive registration in one activity for which other personalized applications such as registration, quick tour and information push can be promoted in the future.

\section{Acknowledgment}

The research is supported by the Ministry of Science and Technology of the Republic of China under the grant number. MOST 107-2511-H-241-002 and MOST 107-3011-F-241-001. Finally, Yi-Chun Chang is the corresponding author.

\section{References}

[1] SIG Bluetooth (2010) 'Bluetooth core specification version 4.0',Specification of the Bluetooth System.

[2] Atanasov, I., Nikolov, A. and Pencheva, E. (2017) 'An approach to transform internet of things data into knowledge', InternationalJournal of Embedded Systems, Vol. 9, No. 5, pp.401-412.

[3] Narendrakumar, S., Razaque, A., Patel, V., Almi'ani, M., Rizvi, S.S. and Hans, A. (2018) 'Token security for internet of things', International Journal of Embedded Systems, Vol. 10, No. 4, pp.334-343.

[4] Hwang, G. J., Hsiao, C. L., \& Tseng, J. C. R. (2003). A computer-assisted approach to diagnosing student learning problems in science courses. Journal of Information Science and Engineering, 19(2), 229-248.

[5] Cheng, S. Y., Lin, C. S., Chen, H. H., \& Heh, J. S. (2005). Learning and diagnosis of individual and class conceptual perspectives: an intelligent systems approach using clustering techniques. Computers \& Education, 44(3), 257-283. 